\title{
El programa emblemático en azulejos de la sacristía del convento de Santo António de Varatojo (Torres Vedras, Portugal)
}

\author{
The emblematic tilework programme of the sacristy at the \\ convent of Santo António de Varatojo \\ (Torres Vedras, Portugal) \\ José Julio GARCÍA ARRANZ \\ Universidad de Extremadura
}

Recibido: 1-X-2017

Aceptado: 21-IV-2018

RESUMEN: La sacristía del convento de Santo António de Varatojo (concejo de Torres Vedras, Portugal) contiene un interesante programa icónico pintado sobre azulejos, atribuido al taller lisboeta del mestre Policarpo de Oliveira Bernardes, uno de los más activos durante el segundo cuarto del siglo XVIII. Realizados hacia 1723-34, estos paneles cerámicos en azul cobalto sobre fondo blanco presentan una decena de composiciones de carácter alegórico, inspiradas en su mayor parte en dos de los más influyentes libros de emblemas religiosos del siglo XVII: la Schola cordis, de Benedictus van Haeften, y los Pia desideria, de Herman Hugo. En el presente trabajo proponemos un análisis de este ciclo conventual, estableciendo sus fuentes precisas, su significación y su contextualización en la historia y funciones del cenobio en el que se ubica.

Palabras clave: Emblemática; Portugal; Azulejos; Convento de Varatojo; Policarpo de Oliveira; Benedictus van Haeften; Herman Hugo.

ABSTRACT: The sacristy of the convent of Santo António de Varatojo (council of Torres Vedras, Portugal) displays an interesting iconic programme painted on tiles, attributed to the Lisbon workshop of the mestre Policarpo de Oliveira Bernardes, one of the most active masters during the second quarter of the eighteenth century. Painted around 1723-34, these ceramic panels of cobalt blue on a white background convey a dozen compositions of allegorical character, being inspired for the most part by two of the most influential books on religious emblems of the seventeenth century: Schola cordis, by Benedictus van Haeften, and Pia desideria by Herman Hugo. This paper presents an analysis of this tile covering, by establishing its precise origins, historical significance and context as well as the function of the monastery where it is found.

Keywords: Emblematics; Portugal; Tiles; Convent of Varatojo; Policarpo de Oliveira; Benedictus van Haeften; Herman Hugo.

\section{EL CONVENTO DE SANTO ANTÓ- NIO DE VARATOJO (TORRES VE- DRAS): SÍNTESIS HISTÓRICA}

El cenobio franciscano de Santo António de Varatojo (Fig. 1) -perteneciente a la fregue- sia de Santa Maria, São Pedro e Matacães, concejo de Torres Vedras, en el área centro-occidental de Portugal, y a unos $50 \mathrm{~km}$ al norte de Lisboa- es un destacado complejo monástico que inició su andadura constructiva en 
el año 1470 a instancias del rey Alfonso V, en cumplimiento de un voto que hiciera a San Antonio para obtener su auxilio en las campañas militares del norte de África ${ }^{1}$. Su solemne inauguración, con la entrada de una primera comunidad compuesta por religiosos procedentes del convento de São Francisco de Alenquer, tuvo lugar apenas cuatro años más tarde, en octubre de 1474 , lo que nos habla de la celeridad de las obras emprendidas. De aquella primera fábrica gótica se conservan, al menos, la portada apuntada occidental de la iglesia, hoy integrada en la portería y flanqueada por las armas del monarca embutidas en el muro ${ }^{2}$, las crujías del primer nivel del claustro, también con arcos ojivales sobre pilares achaflanados ${ }^{3}$, y un corredor-dormitorio, cubierto con bóveda de ladrillo, que conecta con la entrada al coro de la iglesia.

\footnotetext{
${ }^{1}$ El presente trabajo se ha realizado en el marco del proyecto Biblioteca Digital Siglo de Oro 5 (BIDISO 5), con referencia: FFI2015-65779-P, financiado por el Ministerio de Economía y Competitividad del Gobierno de España y el Fondo Europeo de Desarrollo Regional (FEDER). Queremos agradecer la amable colaboración de los frades del convento de Santo António de Varatojo, y muy especialmente la de frey Nicolás Almeida, cuyas facilidades para acceder a la sacristía resultaron esenciales en el proceso de documentación de este estudio.

${ }^{2}$ A la izquierda puede observarse el blasón del monarca fundador, sujeto por ángeles y dispuesto bajo una decorativa tracería gótica; por su parte, a la diestra, se ubicó una de sus divisas personales, un rodillo de agua o rodezno dispersando gotas en todas direcciones, rodeado por un cordón franciscano, elemento con el que, según frei B. RIBEIRO -Convento de Santo António de Varatojo, Torres Vedras, 2005, p. 28-, Alfonso V quería expresar la idea de que el gobernante ha de permanecer en continuo movimiento para servicio y beneficio de su nación.
}

${ }^{3}$ La divisa del rey fundador vuelve a aparecer asociada a cordones franciscanos entrelazados, ahora pintada y reiterada ad infinitum, en la techumbre plana de madera que aún cubre las cuatro galerías de este cuerpo inferior. Las intervenciones continuarán en el espacio claustral en el tránsito del siglo XV al XVI, como evidencian los portales manuelinos que ornan la capilla funeraria de los Alceides-Mores, tanto el que permite el acceso a la misma como el que se conserva en su interior; también al quinientos correspondería el segundo piso del claustro, de estructura adintelada sustentada por columnas.
A mediados del siglo XVI, probablemente como consecuencia del terremoto de

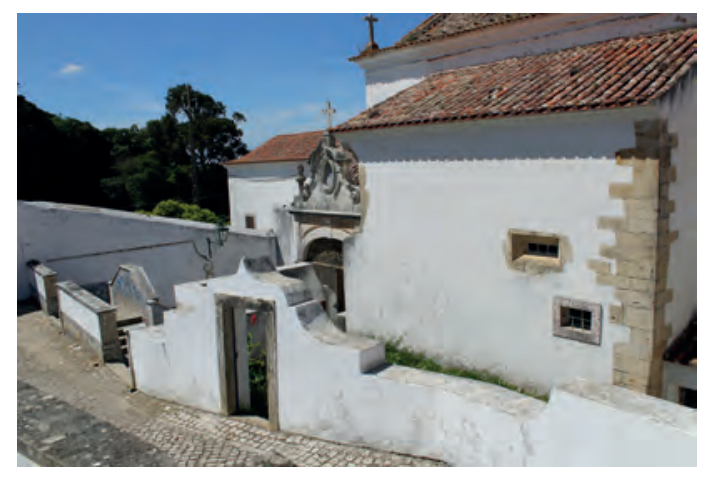

- Fig. 1. Convento de Santo António, Varatojo (Torres Vedras). Detalle del atrio escalonado de acceso al edificio. Foto del autor.

1531, que ocasionaría importantes desperfectos estructurales, el rey João III y su esposa Catarina impulsaron diversas reformas $\mathrm{y}$ añadidos en los dormitorios del costado oriental, en el edificio de enfermería -hoy biblioteca y sala de lectura- y en la capilla mayor de la iglesia. Gracias al incremento poblacional general que vive el país en estas décadas de bonanza, el lugar llegó a albergar a una cincuentena de religiosos.

Desde su mismo origen, estas instalaciones conventuales desempeñaron una labor docente como centro de estudios dependiente de la provincia franciscana de Los Algarves, recibiendo los monjes clases ordinarias de filosofía y teología; a partir de marzo de 1680 el complejo será destinado, por iniciativa del padre frei António das Chagas -fallecido en 1682, cuya sepultura se localiza en la sala capitular del convento-, a seminario autónomo o Colégio de Missionários Apostólicos, sujeto directamente al Ministro General de la Ordem dos Frades Menores, impartiéndose desde entonces las materias y disciplinas apropiadas a su nueva función específica. Con el fin de acomodar al creciente noviciado del seminario se emprendió, entre los años 1739 y 1743, la ampliación de un segundo piso destinado a habitación, labores que se retomarán en fechas más recientes, desde 1903 hasta 1906, con la reserva de algunos de 
estos nuevos espacios para hospedería en la zona oriental del conjunto.

El convento-seminario sufrió las consecuencias desamortizadoras, con la expulsión y dispersión de sus ocupantes llevada a cabo por el gobierno liberal, proceso que culminaría con el decreto de extinción de todas las órdenes y congregaciones religiosas y de expropiación de todos sus bienes firmado por Pedro IV en mayo de 1834. Algunos años más tarde, en 1845, el edificio fue vendido en pública subasta al conde Barão da Torre de Moncorvo; sin embargo, la comunidad de frades franciscanos pudo retornar al convento tras su adquisición al heredero del barón, en 1861

En 1910, con la proclamación de la República Portuguesa y la recuperación de los decretos anticongregacionistas de D. Pedro, el inmueble se transformó en asilo de ancianos. Será gestionado desde 1918 por una Irmandade de Santo António para su mantenimiento después de su declaración como monumento nacional. Una década más tarde el Gobierno nacional cederá a las Misiones Franciscanas el antiguo convento y todas sus dependencias, reinstaurándose a partir de 1940, ya más consolidadas las relaciones entre el Estado portugués y la Iglesia, las funciones de formación que se habían trasladado provisionalmente a Tuy, en Galicia (España), desde 1910, con lo que se establecerá en Varatojo un renovado Noviciado vigente hasta la actualidad ${ }^{4}$.

4 Para los aspectos de carácter histórico-artístico aquí sintetizados nos hemos fundamentado esencialmente en B. RIBEIRO, Op. cit., pp. 13-25, y en F. LOPES, "Últimos días do Seminario Apostólico de Varatojo", Itinerarium, $\mathrm{n}^{\circ}$ 93-94, 1976, pp. 324-338. Cfr. igualmente "Mosteiro de Varatojo", en Património Cultural, página web de la Direção-Geral do Património Cultural, consultada el 18 de julio de 2017. URL: http://www.patrimoniocultural.gov.pt/pt/patrimonio/patrimonio-imovel/ pesquisa-do-patrimonio/classificado-ou-em-vias-declassificacao/geral/view/70223/.

\section{EL ORNAMENTO CERÁMICO DE LA SACRISTÍA}

Dejando ahora al margen otros aspectos arquitectónicos y decorativos de incuestionable interés histórico-artístico presentes en este complejo constructivo, nuestra atención se va a centrar en el aparato ornamental de su sacristía, amplio salón rectangular, de 9,60 por 5,50 m, y 6,50 m de altura hasta la cornisa, sobre la que asienta una bóveda de ladrillo de medio cañón enlucida en blanco (Fig. 2). Sabemos que esta dependencia se encontraba ya finalizada el 26 de diciembre de 1732, fecha de la licencia del Ministro General para celebrar misa en la capelinha da nova Sacristia 5 .

Sin duda, el elemento más llamativo de la estancia es la vistosa serie de paneles figurados de azulejos en cobalto sobre fondo blanco que se extiende por parte de tres de sus muros -norte, sur y oeste; el paramento oriental está ocupado en su casi totalidad por una capilla-altar, dos ventanas y una falsa puerta-, adecuándose a los espacios libres dejados por los vanos, mobiliario y demás aditamentos. Los azulejos se articulan en dos niveles que dividen el alzado de la sala, hasta el cornisamento, en sendas franjas de similar altura. El nivel inferior tan solo cuenta con un par de representaciones alegóricas dispuestas a ambos extremos del muro meridional, cuya zona central está ocupada por el elegante nicho habilitado para aco-

\footnotetext{
${ }^{5}$ Resulta sorprendente que Manoel de Maria Santissima, en su detallado inventario de las principales piezas artísticas conservadas en el convento que publica a fines del siglo XVIII, no repare en los singulares azulejos que aquí nos ocupan en el párrafo que dedica a la sacristía: A Sacristia do Seminário he espaçosa sufficientemente, e com bastante claridade, e se acha adornada de preciosas, $e$ devotas pinturas em quadros; tem altar em que se diz Missa, e duas primorosas mesas, que servem de repositorio para os calices, de marmore preto fino maravilhosamente lavradas, que parecem crystallinos espelhos. Forão trabalhadas estas pedras, como tambem os dous tocheiros da mesma pedra marmore, que estão no presbyterio da Capella Mór pelas mãos do memoravel Irmão Rodrigo de Jesus, Donato do Seminario, $e$ insigne Mestre canteiro (...). Vid. M. de MARIA SANTISSIMA, Historia da Fundação do Real Convento e Seminario de Varatojo, Porto, 1799, Tomo I, pp. 22-23.
} 


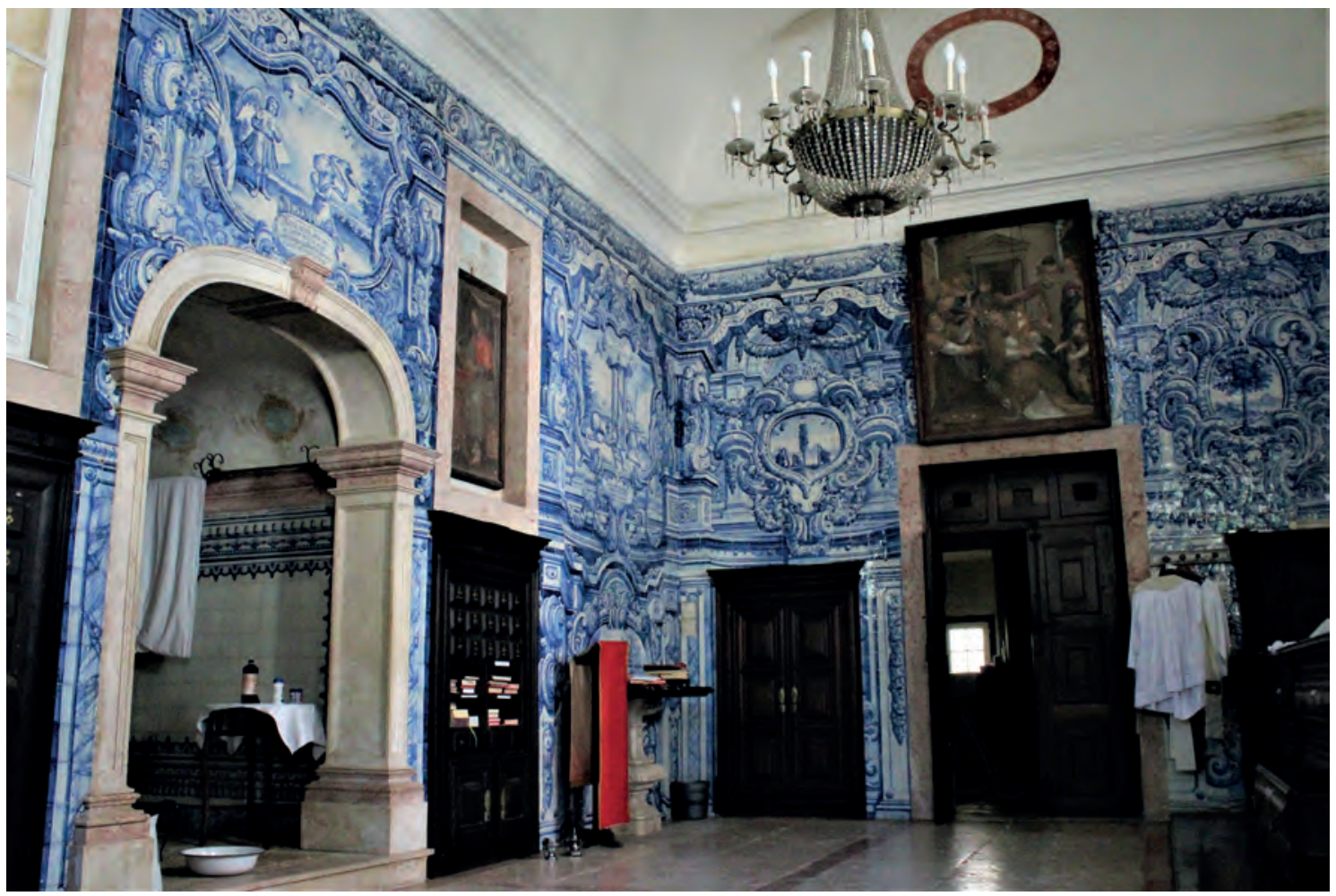

- Fig. 2. Convento de Santo António, Varatojo (Torres Vedras). Vista general de la sacristía. Foto del autor.

ger el lavabo y los armarios empotrados que lo flanquean; estas escenas se inspiran, como veremos más adelante, en emblemas procedentes de los Pia desideria, obra ilustrada del jesuita flamenco Herman Hugo. El segundo registro se encuentra ocupado por las restantes composiciones emblemáticas, seis de ellas derivadas de la Schola cordis, tratado compuesto por Benedictus van Haeften, a las que se suman otros dos jeroglíficos de tema arbóreo, a los lados del cuadro dispuesto sobre la puerta de acceso, en la pared oeste ${ }^{6}$. Hace ya tiempo que José Meco atribuyó estas creaciones al fecundo obrador de Policarpo de Oliveira Bernardes (1695-1778), fundamentándose en los efectos de perspectivas arquitectónicas asociadas a las exuberantes cartelas, volutas, guirnaldas y demás elementos habituales del repertorio

\footnotetext{
${ }^{6}$ Se trata de una pintura anónima sobre tabla, fechada en el siglo XVI, que representa a San Antonio y el milagro de la Eucaristía; en este mismo espacio se conservan en la actualidad otros dos cuadros sobre madera: el Descenso del Espiritu Santo sobre María y los apóstoles, situado frente al anterior, y el evangelista San Lucas, en el muro meridional. Vid. B. RIBEIRO, Op. cit., pp. 35-36.
}

barroco luso, proponiendo para estos revestimientos una fecha entre 1723 y $1734^{7}$. Por nuestra parte, no podemos más que confirmar tal atribución, tanto a la vista de los rasgos estilísticos y excelente calidad de los paneles, como de la incorporación de los ya referidos emblemas protagonizados por árboles, motivos característicos del muestrario icónico auxiliar usado con frecuencia tanto por Policarpo como por su padre António de Oliveira Bernardes (1662-1732) en el taller que ambos regentaron en Lisboa.

Acabamos de indicar que la mayor parte de las composiciones simbólicas con que se reviste la habitación tienen su fuente visual en dos de los más populares y difundidos tratados de la emblemática devocional del seiscientos. Ya frei Bartolomeu Ribeiro

7 J. MECO, Azulejaria portuguesa, Lisboa, 1985, p. 51; ÍDEM, "Le 'cycle des maîtres' baroques", en R. DE SMET (ed.), Azulejos, Bruselas, 1991, pp. 46-47. No deja de resultar sorprendente que J. M. dos SANTOS SIMÕES no haga referencia a este destacado conjunto en su monumental Azulejaria em Portugal no século XVIII, Lisboa, 1979. 
puso de manifiesto, en su monografía sobre el convento ${ }^{8}$, que las escenas altas procedían de las estampas del libro mencionado de Van Haeften (primera edición en Amberes, $1629)^{9}$, apuntando, además, a la vista de los versos en español que se incorporan a las mismas, que tal vez se inspiraran en alguna de las ediciones de la traducción castellana de la obra, la Escuela del corazón, llevada a cabo por el también benedictino fray Diego Mecolaeta ${ }^{10}$; sobre esta cuestión volveremos en otro momento. Sin embargo, no consiguió identificar el origen de las escenas inferiores del muro sur, deudoras, como hemos adelantado, del repertorio de emblemas religiosos más difundido y traducido a distintos idiomas hasta finales del siglo XVIII: los Pia desideria de Herman Hugo, cuya editio princeps vio la luz también en Amberes, en el año $1624^{11}$.

La disposición de los elementos compositivos responde en cada una de las series a un formato ligeramente diferenciado: en los cuadros del registro superior, los derivados de la Schola cordis -donde las características cercaduras barrocas de perfil quebrado enmarcan alegorías de varios estados del alma en su ascenso hacia Dios, siendo el Alma humana figurada como joven doncella y el Amor divino como un ángel- encontramos una estructura tripartita similar a la de la

${ }^{8}$ B. RIBEIRO, Op. cit., pp. 37-41.

${ }^{9}$ B. van HAEFTEN, Schola cordis sive aversi à Deo Cordis ad eumdem reductio, et instructio, Amberes, Hieronymus Verdussen, 1629.

${ }^{10}$ Bartolomeu Ribeiro tan solo menciona la edición de Madrid, 1791 que, evidentemente, es muy posterior a la realización de los azulejos. También la muy difundida impresión de la Escuela del corazón de 1749 se publicaría después de la creación del programa de Varatojo a la vista de las posibles fechas que se han apuntado para el mismo. Sin embargo, la profesora Carme López Calderón, a quien agradecemos encarecidamente esta información, nos habló de la existencia de una primera edición poco conocida de esta versión española, publicada en Madrid en 1720 y que, por tanto, sí podrían haber manejado los autores del programa de azulejos.

${ }^{11}$ H. HUGO, Pia Desideria Emblematis Elegiis $\mathcal{E}$ affectibus SS. Patrum illustrata, Amberes, Hendryck Aertssen, 1624. emblemática libresca. En la parte superior del panel, dentro del campo de representación de la pictura, se inserta en una filacteria el mote del emblema, versículo bíblico en latín identificado mediante la correspondiente cita final; por su parte, en el borde inferior, formando parte de la movida cartela, encontramos un cartucho con una redondilla inscrita en versos castellanos que traducen los dísticos, también en latín, que acompañan a cada emblema original a modo de epigrama. El curioso detalle del idioma de las estrofas llevó a plantear en su momento la posibilidad de que los azulejos fueran obra de procedencia hispana, de talleres de Talavera o Sevilla $^{12}$.

En el caso de las representaciones inspiradas en los Pia desideria, también con alegorizaciones protagonizadas por el Alma y el Amor divino bajo una ingenua apariencia infantil, la configuración anterior se simplifica y se hace ahora bipartita: la escena se dispone en el interior de una cartela elíptica y se acompaña de un único texto que se traslada a una tarjeta situada a un nivel inferior, si bien no sabemos si se trata del lema o de un pasaje aclaratorio, pues ambos paneles aparecen hoy parcialmente cubiertos por las mencionadas mesas de mármol, lo que imposibilita la lectura de tales inscripciones en su práctica totalidad. Por último, en cuanto a los dos motivos arbóreos, el jeroglífico se acompaña de una breve sentencia latina en una filacteria inserta de nuevo en el borde superior del campo de representación de las figuras, sin más añadidos.

\section{DESCRIPCIÓN Y ANÁLISIS DEL PROGRAMA EMBLEMÁTICO DE LA SACRISTÍA}

\section{PANELES INSPIRAdOS EN LA SCHOLA CORDIS}

El monje benedictino Jacques (Benedictus en la orden) van Haeften (1588-1648), que estudió filosofía y teología en la Universidad de Lovaina, es un escritor normal-

\footnotetext{
${ }^{12}$ B. RIBEIRO, Op. cit., p. 38.
} 
mente asociado por la crítica a la corriente rigorista de la primera mitad del siglo XVII. Especialmente interesado por la ascesis, la oración ordinaria y la idea de renuncia, fue autor de dos libros de emblemas que alcanzarán una extraordinaria repercusión durante los siglos XVII y XVIII: la Regia via Crucis, cuya primera edición vio la luz en Amberes en 1625, y la ya referida Schola cordis, ambos traducidos a diversos idiomas, incluido el castellano, conociendo un éxito reseñable y duradero en toda Europa. Haeften se muestra en sus obras espirituales especialmente atento a la humanidad de Cristo y a la figura de Jesús como maestro y guía ${ }^{13}$. La popularidad de estos libros no solo se manifestará en el ámbito espiritual y literario portugués, sino también en el plano artístico, siendo frecuentes en tierras lusas los ciclos derivados de sus estampas, lo que estaría poniendo de manifiesto cierto grado de presencia de ambos tratados, que circularían tanto en sus ediciones latinas como en las traducciones castellanas del setecientos ${ }^{14}$. En cuanto a la

\footnotetext{
${ }^{13}$ L. de MOURA SOBRAL, "A sacristia como pinacoteca da época barroca: o ciclo pictural de Bento Coelho no convento de S. Pedro de Alcântara, Lisboa", en Do sentido das imagens. Ensaios sobre pintura barroca portuguesa e outros temas ibéricos, Lisboa, 1996, pp. 86-87.

${ }^{14}$ Por ejemplo, en el caso de los emblemas de la Regia via crucis, la serie más destacable hasta la fecha es la hoy conservada en el convento da Madre de Deus-Museu Nacional do Azulejo, de Lisboa, con un total de 33 composiciones que aparecen mezcladas de manera un tanto aleatoria con las fundadas en la Schola cordis que describiremos a continuación, con episodios protagonizados por santos eremitas y con escenas y paisajes profanos de diversa índole. El programa fue trasladado y reinstalado en el claustro del convento-museo, procedente del cenobio también lisboeta de religiosos agustinos dos Grilos. El profesor S. SEBASTIÁN LÓPEZ reproduce en su amplio estudio "Los emblemas del Camino real de la Cruz de Van Haeften", Boletín del Museo e Instituto «Camón Aznar», vol. XLIV, 1991, pp. 5-64, hasta 30 de los mencionados emblemas. Además de este ejemplo, resulta bien conocida la inspiración en esta obra de dos series de pinturas de Bento Coelho, fechadas en el último tercio del s. XVII, realizadas sobre los espaldares de unas cajoneras o arcaces conservados en la sacristía de la iglesia conventual lisboeta de San Pedro de Alcántara. Vid. sobre este conjunto, y sobre la presencia de Van Haeften en Portugal, el trabajo citado de L. de MOURA
}

Schola cordis, supone uno de los hitos culminantes de la consolidación del motivo del corazón como uno de los tópicos emblemáticos más extendidos del siglo XVII, cuando el culto al mismo fue recuperado y popularizado por la religiosa Marguerite-Marie Alacoque y el sacerdote Jean Eudes. En esta obra, constituida por 50 emblemas, este órgano anatómico soporta todo tipo de pruebas a modo de "instrucción para que el corazón averso se convierta a Dios"15. Recordemos que los otros dos protagonistas de sus estampas son el Alma humana, a modo de sencilla muchacha vestida con túnica, y el Niño Jesús procedente de la mística provenzal, caracterizado aquí como Amor divino, figura angélica que supone una sublimación del Eros profano derivado de las populares obras ilustradas de Otto Vaenius ${ }^{16}$.

Ya hemos reseñado la presencia en el Museo Nacional del Azulejo de Lisboa, junto a composiciones procedentes de la Regia via crucis, de otros seis emblemas inspirados en la Schola cordis dispuestos en el pretil del claustro alto. Aunque interrumpidos en su seriación con paneles ajenos a esta temática, estos jeroglíficos presentan de izquierda a derecha un orden coincidente con las correspondientes picturae pertenecientes al segundo libro de la obra de Haeften (lectiones 7 a 11). Hasta la fecha no se había procedido a la identificación de tales composiciones -al contrario de lo que sucede con las derivadas del Camino real de la Cruz, analizadas con detalle en el trabajo ya citado de Santiago Sebastián-, por lo que consideramos pertinente enumerarlas a continuación:

Emblema 1: CORDIS INSATIABILITAS (Schola cordis II, 7: Insatiabilis oculus Cupidi. Eccli. 14, 9) (Fig. 3) ${ }^{17}$.

SOBRAL, Op. cit., pp. 81-96.

${ }^{15}$ M. PRAZ, Imágenes del Barroco. Estudios de Emblemática, Madrid, 1989, pp. 164-168.

${ }^{16}$ Ibídem, p. 168.

17 "Insaciabilidad del corazón: El ojo del avaro no se sacia" (Eclesiástico 14, 9). Todas las traducciones de lemas y dísticos latinos proceden de la citada versión 


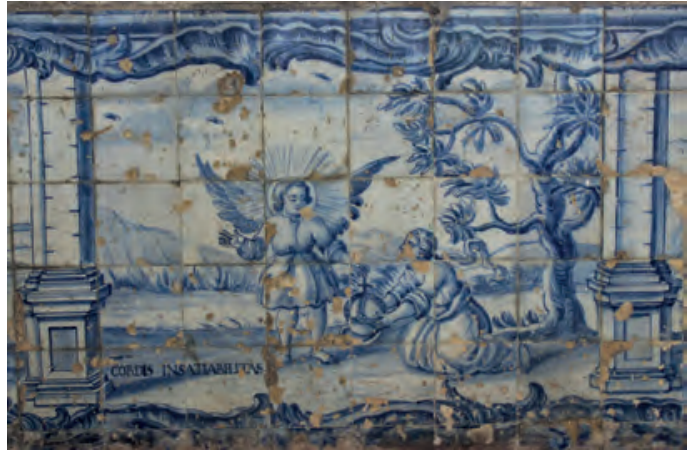

- Fig. 3. Anónimo. Cordis insatiabilitas, composición inspirada en B. van HAEFTEN, Schola cordis, Amberes, 1629 (emblema II, 7). Ca. 1750. Claustro del Museo Nacional del Azulejo, Lisboa. Foto del autor.

Emblema 2: CORDIS REVERSIO (Schola cordis II, 8: Redite praevaricatores ad Cor. Isaiae $46,8)^{18}$.

Emblema 3: CORDIS EFFUSIO (Schola cordis II, 9: Effunde, sicut aquam Cor tuum ante conspectum Domini. Thren. 2, 19) ${ }^{19}$.

Emblema 4: CORDIS CIRCUMCISIO (Schola cordis II, 10: Circumcidite praeputium Cordis vestri. Deuter. 10, 16) ${ }^{20}$.

Emblema 5: CORDIS CONTRITIO (Schola cordis II, 11: Cor contritum, et humiliatum Deus nos despicies. Psalm. 50, 19) ${ }^{21}$.

Emblema 6: CORDIS HUMILIATIO (Schola cordis II, 12: Deprime cor tuum et sustine. Eccli. 2, 2) 22 .

En fechas recientes, la investigadora Filipa Medeiros Araújo, de la Universidad de Coimbra, ha dado a conocer, en una comuni-

castellana de Mecolaeta.

18 "Vuelta al corazón: Entrad en vuestro corazón, prevaricadores" (Isaías 46, 8).

19 "Derramamiento del corazón: Derrama como agua tu corazón ante la presencia del Señor" (Lamentaciones 2, 19).

20 "Circuncisión del corazón: Circuncidad el prepucio de vuestro corazón" (Deuteronomio 10, 16) (cfr. Deuteronomio 30, 6; Génesis 17, 9-14; Jeremías 4, 4).

21 “Quebranto del corazón: Al corazón contrito y humillado no lo despreciarás, oh Dios" (Salmos 51, 19).

22 "Abatimiento del corazón: Humilla tu corazón, y sufre" (Eclesiástico 2, 2). cación presentada al XI Congreso Internacional de la Society for Emblem Studies celebrado en Nancy (Francia) en julio de 201723, la existencia de otro interesante programa setecentista en azulejos derivado de la Schola cordis, hoy conservado en los jardines de la Casa-Museo Bissaya Barreto, en Coimbra, cuya procedencia original todavía se desconoce.

En consecuencia, el conjunto que aquí nos ocupa constituiría la tercera serie conocida hasta la fecha de esta temática y con formato cerámico en tierras lusas. Debemos reseñar que los emblemas seleccionados para el revestimiento de la sacristía de Varatojo proceden de los libros II y III de la obra del benedictino. La enumeración y descripción de los mismos se hará a partir de la puerta de acceso, de izquierda a derecha, siguiendo el sentido de las agujas del reloj, de modo que los tres primeros se alinean en la pared norte -alternando con las dos ventanas-, y los tres restantes en la sur -entre otros dos vanos hoy parcialmente cegados-:

Emblema 1: Circumcidite praeputium CORDIS vestri. Deuteron. 10, $16^{24}$ (Schola cordis, II, 10: CORDIS CIRCUMCISIO -“Circuncisión del corazón"-) (Figs. 4 y 5). El Amor divino ofrece con su mano izquierda un cuchillo al Alma humana, que lo toma mientras sostiene con la izquierda un corazón ornado con una cinta de la que penden varios elementos, todos ellos atributos de las vanidades mundanas: abanico y mechones de plumas, un instrumento musical, un monedero y un espejo; el corazón aparece coronado por un sombrero con orejas y cascabeles como el que portan los bufones. Con este emblema se significa la circuncisión espiritual, la que se opera sobre el corazón humano con el "cuchillo de Dios", que es la palabra divina, ras-

${ }^{23}$ F. MEDEIROS ARAÚJO, "An Open-Air Emblem Book: The Enigmatic Case of the Baroque Tiles in the Garden of the Bissaya Barreto House Museum (Coimbra)", en Actas del XI Congreso Internacional de la Society for Emblem Studies, Nancy, 2017, en prensa.

${ }^{24}$ Este ejemplar es coincidente con el que hemos numerado como emblema 4 en la serie descrita del Museu Nacional do Azulejo de Lisboa. Vid. nota 20. 


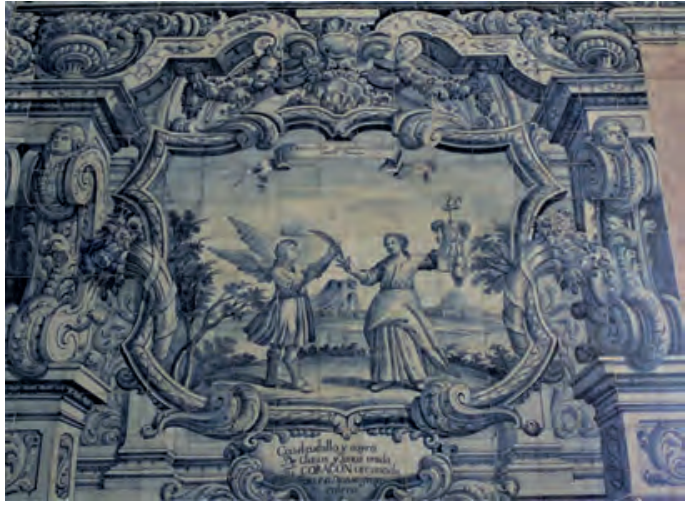

- Fig. 4. Policarpo de Oliveira Bernardes (atrib.). Circumcidite praeputium Cordis vestri, composición inspirada en B. van HAEFTEN, Op. cit., (emblema II, 10). Ca. 1723-1734. Sacristía del convento de Santo António, Varatojo (Torres Vedras). Foto del autor.

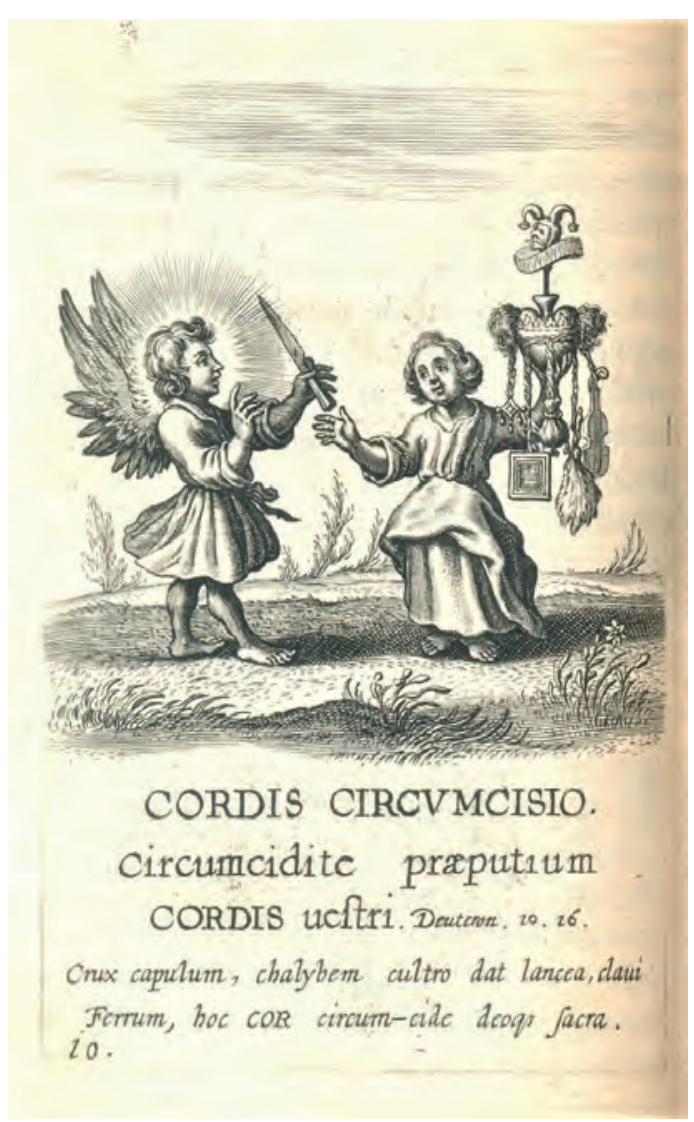

- Fig. 5. Boetius à Bolswert, Circumcidite praeputium Cordis vestri. B. van HAEFTEN, Op. cit. (emblema II, 10). Propiedad del autor.

gando este órgano, esto es, cercenando los malos pensamientos, los afectos desordenados y las inquietudes materiales que pueden manchar el alma, para poder presentarlo limpio a los ojos del Señor.

"Con el cuchillo, y azero,

De clavos, y lança unida,

Tu CORAÇÓN circuncida,

Porque á Dios se ofrezca entero" ${ }^{25}$.

Emblema 2: Tetendit arcum suum, et posuit me quasi signum ad Saggitam. Thren. 3. $12^{26}$ (Schola cordis III, 14: CORDIS VULNERATIO -“Llagadura del corazón”-) (Fig. 6). El Amor divino, armado con arco y carcaj, acaba de disparar una flecha que se ha clavado en el corazón que sostiene en su regazo el Alma humana; esta se encuentra sentada, apoyando la cabeza sobre su mano derecha en actitud meditativa. Mediante esta alegoría se indica que Dios lanza sus flechas de caridad y amor sobre el alma elegida y dichosa amante de su Creador, de modo que se abre una herida por la que penetran en lo más íntimo los más saludables y piadosos afectos.

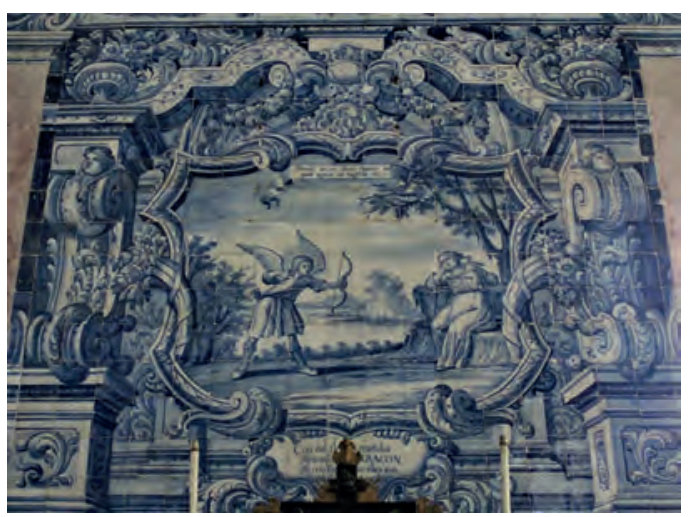

- Fig. 6. Policarpo de Oliveira Bernardes (atrib.), Tetendit arcum suum, et posuit me quasi signum ad Saggitam. Composición inspirada en B. van HAEFTEN, Op. cit. (emblema III, 14). Ca. 17231734. Sacristía del convento de Santo António, Varatojo (Torres Vedras). Foto del autor.

${ }^{25}$ Dístico latino original: Crux capulum, chalybem cultro dat lancea, / clavi Ferrum, hoc COR circumcide Deoque sacra; traducción de Diego Mecolaeta: "Dale a Dios tu corazón, / Después de circuncidado; / Que los que cuchillo han dado, / Cruz, clavos y lanza son".

26 "Entesó su arco, me puso como blanco a la saeta" (Lamentaciones 3, 12). En este emblema se intensifican las afinidades entre el Amor divino y el Cupido clásico. 
"Con mil flechas repetidas Me traspassa el CORAÇÓN, Tierno Esposo, que ellas son, La salud de mis heridas" ${ }^{27}$.

Emblema 3: Devisum ${ }^{28}$ est COR eorum, nunc interibunt. Oseae 10. $2^{29}$ (Schola cordis II, 6: CORDIS DIVISIO -“División del corazón”-). El Alma, situada en pie, ofrece con la mano izquierda la mitad de su corazón a una dama, vestida con rico atuendo y con un orbe crucífero sobre la cabeza -personificación del poder mundano-, que recoge sonriente la ofrenda; con la otra mano, el Alma presenta la otra parte del corazón al Amor divino, que, alzando sus brazos y girando la cabeza hacia otro lado, rechaza el ofrecimiento. Con esta escena se representa el hecho de que Dios, como amante celoso, no consiente que el alma comparta el corazón que le fue entregado por Él con otros consortes, como son los deseos terrenos o las tentaciones diabólicas, que distraen su debida fidelidad, pues no puede el hombre "servir a dos amos opuestos"; Dios exige, en consecuencia, que le amemos con todas nuestras capacidades.

\section{"Si me he dado enternecido Todo à ti, querida Esposa, Porque me dás desdeñosa Tu CORAÇÓN dividido" ${ }^{30}$.}

Emblema 4: Quae sursum sunt quaerite, quae sursum sunt sapite. Coloss. 2, $1^{31}$ (Schola cordis: III, 17: CORDIS VOLATUS -“Vue-

${ }^{27}$ Dístico latino original: Mille COR hoc validis, mea lux, transfige sagitis, / Pharmaca sunt, tua, quae vulnera dextra facit; traducción de Diego Mecolaeta: "Traspasen mi corazón / Tus saetas, luz querida, / Pues tus flechas de la herida / Dulce medicina son".

${ }^{28}$ Divisum en el lema original.

29 "Tienen dividido su corazón, ahora perecerán" (Oseas 10, 2).

${ }^{30}$ Dístico latino original: Me tibi cum totum dederim, vanissima, CORDIS, / Cur mihi, virgo, tui pars aliquanta datur?; traducción de Diego Mecolaeta: “Todo el corazón te di / Ingrata, por obligarte; / ¿Y tú con sola una parte / Quieres contentarme a mí?".

31 "Buscad las cosas que son de arriba, pensad en las cosas de arriba" (Colosenses 2, 1; 3, 1-2). lo del corazón"-) (Fig. 7). En medio de un paraje rural en el que se distinguen diversas construcciones, el Alma humana, puesta de pie y con los brazos abiertos en actitud extática, contempla cómo su corazón alado se eleva hacia el Amor divino, que, surgiendo de entre unas nubes en el cielo, se dispone a recogerlo con ambas manos. El emblema nos indica que, para evitar la dolorosa ausencia del Señor que supone nuestra vida mortal, debemos poner en práctica la vía contemplativa y elevar nuestra atención hacia el cielo -lo que se simboliza mediante el corazón alado que asciende hacia la gloria, mostrada mediante la figura del Amor divino entre nubes-, renunciando a lo material para alcanzar los gozos y la paz de la salvación eterna.

“O quién al Cielo volara, Con tan presuroso buelo

De su CORAÇÓN, que al Cielo En un instante llegara" ${ }^{32}$.

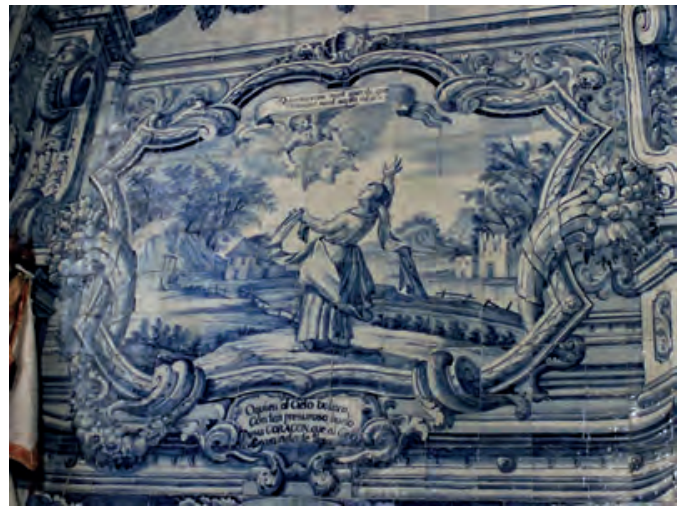

- Fig. 7. Policarpo de Oliveira Bernardes (atrib.), Quae sursum sunt quaerite, quae sursum sunt sapite. Composición inspirada en B. van HAEFTEN, Op. cit. (emblema III, 17). Ca. 1723-1734. Sacristía del convento de Santo António, Varatojo (Torres Vedras). Foto del autor.

Emblema 5: Deus mollivit COR meum. Iob. 23. $16^{33}$ (Schola cordis II, 13: CORDIS EMOLLI-

${ }^{32}$ Dístico latino original: Quis mihi Chaonii geminas dabit alitis alas, / Pertaesum terrae queis COR ad astra volet; traducción de Diego Mecolaeta: “iQuién alas al corazón / Dará, con que vuele al cielo! / Porque enfadado del suelo / Allá aspira su afición".

33 “Dios ha enmollecido mi corazón” (Job 23, 16). 
TIO -“Ablandamiento del corazón"-) (Fig. 8). El Amor divino, puesto en pie, proyecta uno de los haces de rayos que surgen de su cabeza -representación de la clemencia divina- sobre un corazón que el Alma humana, puesta de rodillas y protegiendo sus ojos de los resplandores con el extremo del manto, presenta a su compañero, de modo que dicho órgano se está derritiendo en forma de gotas. Se representa de este modo el concepto de que la clemencia y el amor divinos se manifiestan con tal intensidad que llegan a ablandar los más obstinados corazones, eliminando su pesadez, rigor y rudeza, y propiciando su unión mística con Jesús.

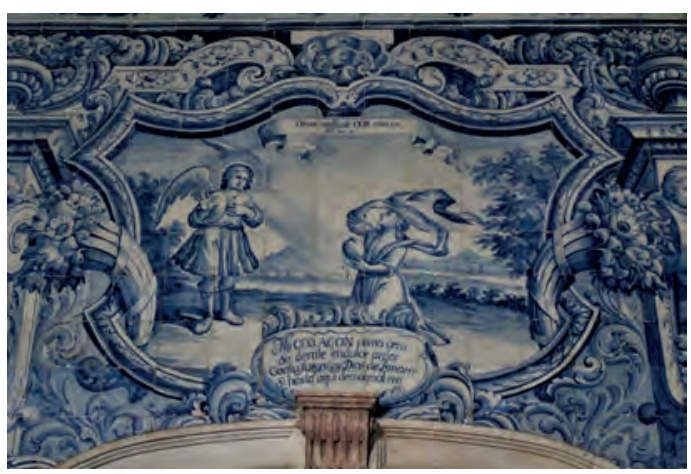

- Fig. 8. Policarpo de Oliveira Bernardes (atrib.), Deus mollivit Cor meum. Composición inspirada en B. van HAEFTEN, Op. cit. (emblema II, 13). Ca. 1723-1734. Sacristía del convento de Santo António, Varatojo (Torres Vedras). Foto del autor.

\section{“Mi CORAÇÓN como cera}

Se derrite en dulce ardor

Con tu fuego (ay Dios de Amor!)

Si hasta aquí de mármol era" ${ }^{\prime 34}$.

Emblema 6: Deprime COR tuum et Sustine. Eccli. 2. ${ }^{35}$ (Schola cordis II, 12: CORDIS HUMILIATIO -“Abatimiento del corazón"-)

${ }^{34}$ Dístico latino original: COR, marmor glaciale, Deus, ceu cera, liquescet, / Urere cum tuus hoc caeperit ignis amor; traducción de Diego Mecolaeta: “Mi corazón, mármol frío / En cera verás trocar, / Si lo llega a calentar / Un rayo de amor, Dios mío".

${ }^{35}$ Este ejemplo es coincidente con el que hemos numerado como emblema 6 en la serie descrita del Museu Nacional do Azulejo de Lisboa. Vid. nota 22.
(Fig. 9). El Alma humana, postrada en el suelo y con los ojos cerrados en actitud de humildad, deposita con ambas manos el corazón debajo de una prensa, cuyo tornillo es accionado con esfuerzo por el Amor divino. Con este emblema se pone de manifiesto la proximidad entre los conceptos de humildad y penitencia y el hecho de que es en la mansedumbre del corazón que huye de soberbias y ambiciones donde se encuentra el reposo de las almas; muestra, además, que el camino de la sumisión, el sacrificio y el sufrimiento es el más seguro y efectivo para que el alma pueda ser finalmente ensalzada y se eleve hacia Dios hasta obtener la ansiada unión mística.

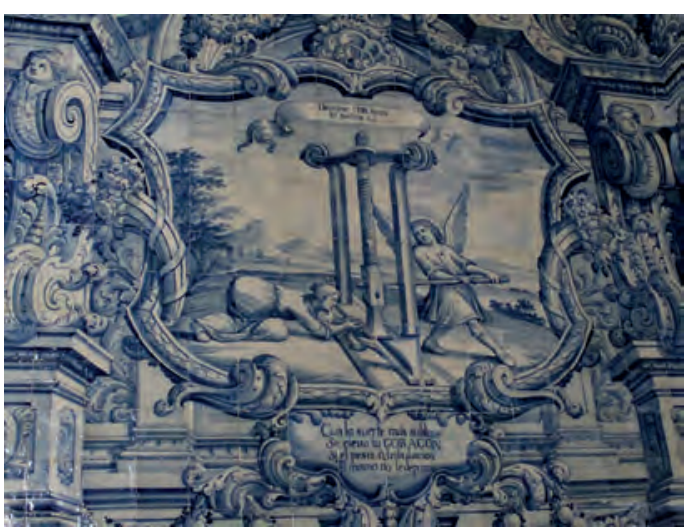

- Fig. 9. Policarpo de Oliveira Bernardes (atrib.), Deprime cor tuum et sustine. Composición inspirada en B. van HAEFTEN, Op. cit. (emblema II, 12). Ca. 1723-1734. Sacristía del convento de Santo António, Varatojo (Torres Vedras). Foto del autor.

"Con la suerte más sublime
Se eleva tu CORAÇÓN,
Si el peso, ó tribulación
Al mismo no le deprime"36.

EMblemAS DE TEMA ARBóREO

Como ya hemos indicado en trabajos anteriores ${ }^{37}$, estos dos jeroglíficos dispuestos

${ }^{36}$ Dístico latino original: COR, nimis, heu, sese, gaudens sublimibus, effert; / Ni super impositum, deprimat illud onus; traducción de Diego Mecolaeta: “Si una prensa no deprime / La altivez del corazón, / ¿Querrá ascender su elación / A la esfera más sublime?".

${ }^{37}$ Vid. J. J. GARCÍA ARRANZ, “Emblemática inma- 
en el segundo nivel del testero occidental de la sacristía de Varatojo son símbolos que forman parte de un repertorio de temática preferentemente vegetal, prefijado y usado con frecuencia por el taller de azulejos de la familia Oliveira Bernardes como complemento significativo de composiciones o escenas relativas a la exaltación de la Virgen María, especialmente en su vertiente inmaculista. En consecuencia, nos resulta cuando menos curiosa, por falta de conexión temática aparente, la incorporación de las figuras del laurel y el cedro, claras alusiones a determinados atributos o virtudes marianas, en combinación con la serie de emblemas destinados a la función introspectiva de meditación monástica que acabamos de describir. Tampoco guardan relación alguna con las pinturas sobre tabla que hoy se conservan en la estancia. No parecen, por tanto, formar parte integrada del discurso que se desprende del aparato icónico de la sacristía: creemos que más bien se trata de paneles de "relleno", con una temática piadosa, pero con composiciones más simplificadas, adecuadas para la cubrición de unos espacios de más reducidas dimensiones.

Emblema 7: Comenzando por la izquierda, la pictura del emblema nos muestra diversos árboles quebrados por el tronco y derribados, entre los que un laurel, situado en el centro, se mantiene en pie con sus ramas y fronda íntegras, bajo el lema INTACTA TRIUMPHAT -“Intacto triunfa" - (Fig. 10). El jeroglífico se basa en la cualidad atribuida al laurel en diversos textos clásicos ${ }^{38}$ y medie-

culista en la azulejería barroca portuguesa: el programa de la iglesia parroquial das Mercês de Lisboa", en I. ARRELLANO y A. MARTÍNEZ PEREIRA (eds.), Emblemática y religión en la Península Ibérica (Siglo de Oro), Bilbao, 2010, p. 171; ÍDEM, "Jeroglíficos en la azulejería barroca portuguesa del siglo XVIII al servicio de la retórica eclesiástica: los programas de António y Policarpo de Oliveira Bernardes", en I. RODRÍGUEZ MOYA, M. Á. FERNÁNDEZ VALLE y C. LÓPEZ CALDERÓN (eds.), Arte y patrimonio en Iberoamérica. Tráficos transoceánicos, Castelló de la Plana, 2016, p. 50.

${ }^{38}$ C. PLINIO EL VIEJO, Historia natural, F. MANZANERO CANO, I. GARCÍA ARRIBAS, M. L. ARRIBAS HERNÁEZ, A. M. MOURE CASAS y J. L. SANCHO

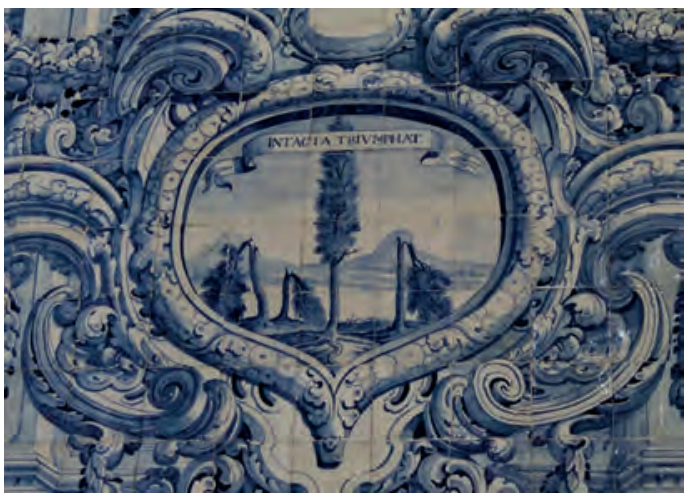

- Fig. 10. Policarpo de Oliveira Bernardes (atrib.), jeroglífico del laurel con el lema Intacta triumphat. Ca. 1723-1734. Sacristía del convento de Santo António, Varatojo (Torres Vedras). Foto del autor.

vales $^{39}$ según la cual sus hojas no son nunca heridas por el rayo: ello explica que este árbol se mantenga erguido y frondoso entre otros arrasados por la tormenta, razón por la que en la literatura humanista se consolidó como jeroglífico de Custodia y Seguridad ${ }^{40}$. La posible fuente de esta empresa se localiza en Filippo Picinelli, quien escribe a propósito de ella: "El laurel muy bello y floreciente en medio de otros árboles derribados por el rayo, ostenta el lema INTACTA TRIUMPHAT, el cual cuadra a la Virgen María que fue la única entre las demás criaturas que no fue golpeada por el rayo del pecado" ${ }^{\prime 4}$.

BERMEJO (trad. y notas), Madrid, 2010, Libro XV, p. 134; C. SUETONIO TRANQUILO, "Tiberio" y "Augusto", en Vidas de los Césares, V. PICÓN (ed.), Madrid, 2008, pp. 69 y 90 respectivamente. Sobre esta propiedad del laurel, ver R. GARCÍA MAHÍQUES, Flora emblemática. Aproximación descriptiva del código icónico, Valencia, 1991, 2 vols. (ed. en microfichas), vol. I, pp. 390-391.

${ }^{39}$ ISIDORO DE SEVILLA, Etimologías, J. OROZ RETA y M. Á. MARCOS CASQUERO (texto latino y español y notas), Madrid, 2004, Libro XVII, 7, 2.

${ }^{40}$ G. P. VALERIANO, Hieroglyphica sive de sacris aegyptiorum, aliarumque gentium literis commentarii, Basilea, Thomam Guarinum, 1567, Lib. L, p. 372.

${ }^{41}$ F. PICINELLI, Mondo simbolico, Milán, Francesco Vigone, 1680, I parte, Lib. IX, Cap. III, 17, p. 408, s. v. Alloro. La traducción procede de la realizada por Eloy Gómez Bravo como borrador para la edición del libro IX, actualmente en prensa, del Mundo simbólico de Filippo Picinelli («Los árboles, sus frutos y sus propiedades»), que gentilmente nos proporcionó Bárbara Skin- 
Este mismo jeroglífico fue incluido de igual modo en el recubrimiento cerámico de la estancia en forma de galería que pone en comunicación la cabecera del templo con otras dependencias interiores en la iglesia das Mercês - del antiguo monasterio franciscano de Jesús-, en Lisboa ${ }^{42}$, que Luís de Moura Sobral interpreta como una antigua capilla dedicada a la Inmaculada Concepción ${ }^{43}$.

Emblema 8: En el segundo panel, situado a la derecha de la puerta, vemos a una serpiente alada o dragón que huye del tronco de un cedro, con la letra ODORE FUGAT $S U O$-“Huye con su olor"-. El cedro es árbol de rica significación bíblica, y los del Líbano fueron especialmente celebrados en la Antigüedad por su majestuosa altura y su madera incorruptible y aromática, cualidades que justifican su incorporación a la emblemática mariana. Para el simbolismo del presente emblema, el lugar común es el comentario de Cornelio a Lapide, quien, a propósito de su suave olor, afirma: "[...] el cedro es, en efecto (árbol) perfumado, y por ello incorruptible y eterno. Es por ello que el cedro, con su olor, pone en fuga y mata a las serpientes" ${ }^{\prime 4}$. La

fill.

${ }^{42}$ J. J. GARCÍA ARRANZ, “Emblemática inmaculista...", pp. 153-154; ÍDEM, "Jeroglíficos en la azulejería barroca...", p. 39. Ya Luís de MOURA SOBRAL, en su trabajo "Tota pulchra est amica mea. Simbolismo e narração num programa imaculista de António de Oliveira Bernardes", Azulejo, no 3/7, 1995-1999, p. 88, puso de manifiesto, muy brevemente, la coincidencia de algunos de los medalhões emblemáticos de la iglesia das Merçes con los existentes en Varatojo. Por otra parte, hemos localizado este mismo jeroglífico en la base de uno de los paneles de azulejos hoy instalados en el parque del Museu Castro Guimarães, en Cascais, fechados hacia 1750 y que, según J. M. dos SANTOS SIMÕES -Op. cit., p. 188-, seguramente provengan de un convento de monjes teatinos, a juzgar por su temática. El panel referido está en la parte alta del jardín, en una pared al fondo de un estanque y representa el "cortejo triunfal" de Nossa Senhora de Conceição, que aparece sentada en un ornamentado carro.

${ }^{43}$ L. de MOURA SOBRAL, Tota pulchra est amica mea..., p. 77.

${ }^{44} \mathrm{C}$. a LAPIDE, Commentarii in ecclesiasten, París, Ludovicus Vives, 1878, IX, pp. 633-634. empresa aparece también con frecuencia en otros conjuntos realizados por los Oliveira Bernardes: es el caso del revestimiento del rodapié tanto de la ya mencionada galería en la iglesia lisboeta das Mercês, como de la nave del santuario dos Remédios, en Peniche, y de una de las pechinas de la cúpula de la capela de Nossa Senhora da Cabeça, en Évora ${ }^{45}$; fue figura de igual modo insertada en uno de los lunetos que configura la bóveda de crucería de la sacristía de la catedral de Portalegre ${ }^{46}$.

Composiciones INSPIRADAS EN LOS PIA DESIDERIA

Herman Hugo (1588-1629), nacido en Bruselas, fue un sacerdote jesuita y profesor de Humanidades en Amberes, confesor del duque de Aerschot y limosnero del capitán Ambrosio Espínola, falleciendo en una de sus campañas a consecuencia de la peste que asoló Rheinsberg en septiembre de 1629. Su obra más celebrada, los Pia Desideria -“Deseos piadosos"-, que dedicó al pontífice Urbano VIII, fue posiblemente el mejor conocido de los libros de emblemas jesuíticos, pues es el que cuenta con el mayor número de adaptaciones a otras lenguas europeas hasta finales del siglo XVIII -42 ediciones latinas y traducciones vernáculas-, incluyendo la existencia de versiones protestantes. Como se ha señalado en diversas ocasiones, los emblemas del jesuita responden al "procedimiento ignaciano de contemplación divina, recuperando el lenguaje alegórico del Cantar de los cantares" a través de una estructura argumental en tres partes -vías purgativa, iluminativa y unitiva, esto es, purificación activa, desarrollo de la contemplación y gozos de la unión divina-, en un proceso de ascesis mística y crecimiento de la vida interior que

${ }^{45} \mathrm{~J}$. J. GARCÍA ARRANZ, “Emblemática inmaculista...", pp. 159-160; ÍDEM, "Jeroglíficos en la azulejería barroca portuguesa...", pp. 40 y 42 .

${ }^{46}$ M. do R. S. DE CARVALHO, "A pintura do azulejo em Portugal [1675-1725]. Autorias e biografías - um novo paradigma", Tesis doctoral defendida en la Universidade de Lisboa, Faculdade de Letras, Departamento de História, 2012, anexo b, p. 1090. 
reproduce el camino recorrido por el Alma hasta encontrarse con su Divino Esposo ${ }^{47}$. Sin duda la feliz conjunción de "grabados descriptivos de las metáforas sagradas" y las "elegías piadosas" determinó el éxito inmediato de la obra a través del "encantador" aspecto infantil de los personajes, y de unos atributos místicos familiares a sus potenciales lectores ${ }^{48}$.

La presencia de este célebre tratado ilustrado de meditación en la literatura y las artes del barroco portugués es un asunto que viene suscitando interés desde hace tiempo. Ya Maria de Lourdes Belchior Pontes planteó tal cuestión en una monografía de $1953^{49}$, siendo contestada in extenso, varias décadas más tarde, en sendos trabajos que pueden considerarse ya "clásicos" sobre esta temática como son los de J. Adriano de Freitas Carvalho ${ }^{50}$ y Pedro F. Campa en tor-

${ }^{47}$ G. R. DIMLER, “Herman Hugo's Pia Desideria”, en K. A. E. ENENKEL y A. S. Q. VISSER (eds.), Mundus Emblematicus. Studies in Neo-Latin Emblem Books, Turnhout, 2003, pp. 351-379; J. J. AZANZA y R. ZAFRA, Deleitando enseña: una lección de emblemática. Libros de emblemas en la Universidad de Navarra, Pamplona, 2009, pp. 42-43; F. MEDEIROS ARAÚJO, Verba significant, res significantur: a receção dos Emblemata de Alciato na produção literaria do Barroco em Portugal, Tesis doctoral defendida en la Universidad de Coimbra, 2014, p. 117.

${ }^{48}$ A. E. SPICA, Symbolique humaniste et emblematique: L'evolution et les genres (1580-1700), Paris, 1996, pp. 352354. También M. PRAZ-Op. cit., pp. 159-160- subraya el hecho de que la popularidad de estos emblemas corrió pareja al ya mencionado culto seicentista al Niño Jesús, asociado a una sociedad acostumbrada a representar el amor humano bajo el aspecto de Eros alejandrino, y a la selección por parte del autor de unas citas adaptadas a la sensibilidad de la época, como el Cantar de los cantares o los Salmos, "textos cuyas metáforas sugerían inevitablemente emblemas, con la voluptuosidad oriental de su atractivo para los sentidos".

${ }^{49}$ M. de L. BELCHIOR PONTES, Frei António das Chagas. Um Homem e um Estilo do Séc. XVII, Lisboa, 1953, p. 341 .

${ }^{50} \mathrm{~J}$. A. de FREITAS CARVALHO, "As lágrimas e as setas. Os Pia Desideria de Herman Hugo, S. J. em Portugal", Via spiritus, 2, 1995, pp. 169-201. Este autor señala, en las páginas 173-176, que contamos con diversos indicios que parecen revelar una larga tradición de conocimiento y aprecio de los Pia desideria, y, por tanto, una circulación de la obra que se remontaría, al menos, a los no al análisis de los Desejos piedosos de huma alma saudosa do seu divino Esposo Jesu Christo, Lisboa, Miguel Deslandes, 1687 (edición a la que siguieron, al menos, otras tres en 1688, 1725 y 1754), de José Pereira Veloso, como adaptación portuguesa del libro jesuita ${ }^{51}$. En cuanto a su trascendencia en las artes plásticas lusas, João Pedro Monteiro dio noticia en 1995 de la existencia de dos interesantes programas sobre azulejos inspirados en este tratado, localizados, respectivamente, en la iglesia de la Santa Cruz de Santarém y en la sala capitular del antiguo convento -hoy hospital- de Santa Marta, en Lisboa, ambos fechados en las primeras décadas del s. XVI$\mathrm{II}^{52}$. En una comunicación presentada recientemente en el XI Congreso de la Society for Emblem Studies en Nancy (Francia) en julio de 2017, la profesora Reyes Escalera Pérez y el autor de estas páginas revisábamos y actualizábamos la presencia de esta temática en la azulejería portuguesa de la primera mitad del siglo XVIII, analizando hasta cuatro programas entre los que se incluye el que aquí vamos a describir del convento de Varatojo ${ }^{53}$.

años centrales del seiscientos. Tal interés cristalizó en la ya citada versión portuguesa del libro del jesuita belga, los Desejos piedosos de Pereira Veloso -Op. cit., p. 178-.

${ }^{51}$ P. F. CAMPA, "The Spanish and Portuguese Adaptations of Herman Hugo's Pia Desideria", en P. M. DALY y D. S. RUSSELL (eds.), Emblematic Perceptions: Essays in Honour of William S. Heckscher on the Occasion of his Ninetieth Birthday, Baden-Baden, 1997, p. 43. Existe también traducción española del tratado: P. de SALAS, Affectos divinos con emblemas sagradas, Valladolid, Gregorio de Bedoya, 1658.

52 J. P. MONTEIRO, “Os 'Pia desideria', uma fonte iconográfica da azulejaria portuguesa do século XVIII", Azulejo, no 3/7, 1995-1999, pp. 61-70. Sobre el segundo de estos conjuntos ha visto la luz en fechas más recientes un trabajo de T. MOITA, “Os Azulejos do Mestre P. M. P. da sacristia da igreja de Santa Cruz da Ribeira de Santarém: um itinerário místico e eucarístico", en A. GAGO da CÂMARA y S. COSTA SALDANHA (coords.), Ciclos de Iconografia Cristã na Azulejaria. Actas do I Colóquio Sacrae Imagines, Lisboa, 2013, pp. 179-188.

${ }^{53}$ R. ESCALERA PÉREZ y J. J. GARCÍA ARRANZ, "Herman Hugo y Benedictus van Haeften en Portugal: los programas de emblemas devocionales en la azulejería portuguesa del siglo XVIII". El artículo se encuentra actualmente en prensa para las Actas de dicho congreso. 
Resulta muy probable que en la biblioteca del cenobio se dispusiera de algún ejemplar de los Pia desideria, como parece deducirse del hecho de que el ya mencionado frei António das Chagas compusiera una serie de Cánticos inspirados en los emblemas jesuitas, que no constituyen una traducción literal del epigrama (suscriptio) de cada emblema de Hugo, sino creaciones propias que, partiendo del concepto emblemático original, proponen un sumario de doctrina cristiana bajo el formato de inspiradas estrofas ${ }^{54}$. Tales versificaciones fueron incorporadas por José Pereira Veloso a su ya referida obra, que supone, por lo demás, una adaptación bastante libre del tratado original latino ${ }^{55}$. Sin embargo, los distintos detalles de los paneles cerámicos de la sacristía de Varatojo parecen indicar que el artista que los realizó se inspiró en los grabados de alguna de las ediciones latinas derivadas de la princeps de 1624 .

Como ya hemos indicado, son dos las composiciones emblemáticas del convento portugués inspiradas en el libro de Hugo, de izquierda a derecha:

Emblema 9: Deus é a luz que atrai as almas sedentas de amor ${ }^{56}$ (Pia desideria II, 8: Trahe me post te, curremus in odorem unguentorum tuorum. Cant. 1; "Llévame, Señor, tras ti correremos al olor de tus ungüentos" (Cantar de los Cantares 1, 3-4) (Figs. 11 y 12). El Alma humana, recostada en el suelo, trata de arrastrarse penosamente tras el Amor divino, que

${ }^{54}$ M. de L. BELCHIOR PONTES, Op. cit., p. 389.

\footnotetext{
${ }^{55} \mathrm{~J}$. A. de FREITAS CARVALHO, Op. cit., p. 178.
}

${ }^{56}$ Ya indicamos que, detrás de los pies de las mesas barrocas de mármol que enmascaran ambos emblemas, se intuyen tituli con inscripciones que hoy no resultan legibles; tal vez esta leyenda en portugués, que frei B. RIBEIRO -Op. cit., p. 41- incluye como "sentido" del emblema, al igual que la siguiente, sean reproducción de sendas sentencias que pudo llegar a leer, si bien no especifica nada al respecto. Por otra parte, esta composición emblemática aparece también incluida en el revestimiento azulejar de la Casa da Irmandade de la iglesia de Santa Cruz da Ribeira, en Santarém, programa fechado en 1723 y atribuido al monogramista anónimo P. M. P. Vid. J. P. MONTEIRO, Op. cit., p. 61, y T. MOITA, Op. cit., p. 183, fig. 4. corre por delante de ella portando un incensario cuyos vapores llegan al rostro de la joven; esta se encuentra asida a una cuerda con la cual el Amor parece conducirla tras de sí. Se representan así las dificultades y tribulaciones que ha de padecer nuestra ánima para poder seguir los pasos del Verbo divino a pesar de la dulce promesa de la gloria que emana de sus fragantes aromas -imagen de sus palabras y doctrina-, pudiendo tan solo servirse como ayuda de la fuerte "cinta" del don de su gracia.

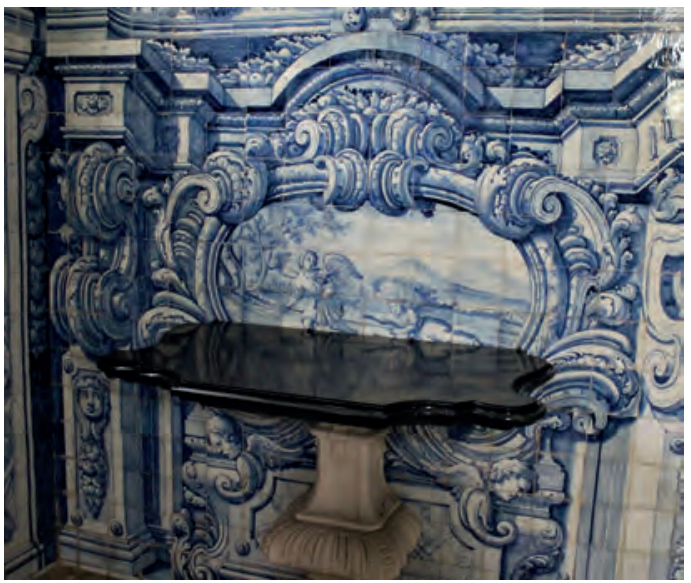

- Fig. 11. Policarpo de Oliveira Bernardes (atrib.), Deus é a luz que atrai as almas sedentas de amor. Composición inspirada en H. HUGO, Pia Desideria, Amberes, 1624 (emblema II, 8). Ca. 17231734. Sacristía del convento de Santo António, Varatojo (Torres Vedras). Foto del autor.

Emblema 10: Como o veado anseia pelas águas vivas, assim mina alma suspira por vós, meu Deus ${ }^{57}$ (Pia desideria III, 11: Quemadmodum desiderat cervus ad fontes aquarum, ita desiderat anima mea ad te, Deus! Psal. 41; (Salmos 42, 2). "Como el ciervo desea las fuentes de agua, ansí te desea mi alma Dios, y Señor mío". En la composición aparece el alma cabalgando "muy ayrosa" a lomos de

${ }^{57} \mathrm{Vid}$. nota anterior. Este mismo motivo emblemático aparece también incluido en el programa que decora la sala capitular del antiguo convento, hoy hospital, de Santa Marta de Lisboa, atribuido a Valentim de Almeida y realizado hacia 1740 . Vid. J. P. MONTEIRO, Op. cit., p. 65; A. J. de BARROS VELOSO e I. AMASQUÉ, História e azulejos dos hospitais civis de Lisboa, Lisboa, 2016, pp. 116-117. 
un ciervo que la conduce a gran velocidad hacia una fuente, sobre cuya taza cilíndrica aparece la figura en pie del Amor divino, con sus brazos alzados y extendidos; de las llagas de sus manos, pies y pecho fluyen cinco surtidores de sangre. Con ello se representa al alma "sedienta" -deseosa de saciarse en las perpetuas fuentes de la vida eterna-, que acude presurosa a lomos de un ciervo hacia tan dulces aguas que emanan del Verbo divino.

\section{ALGUNAS CONSIDERACIONES FINALES}

El programa icónico de la sacristía del

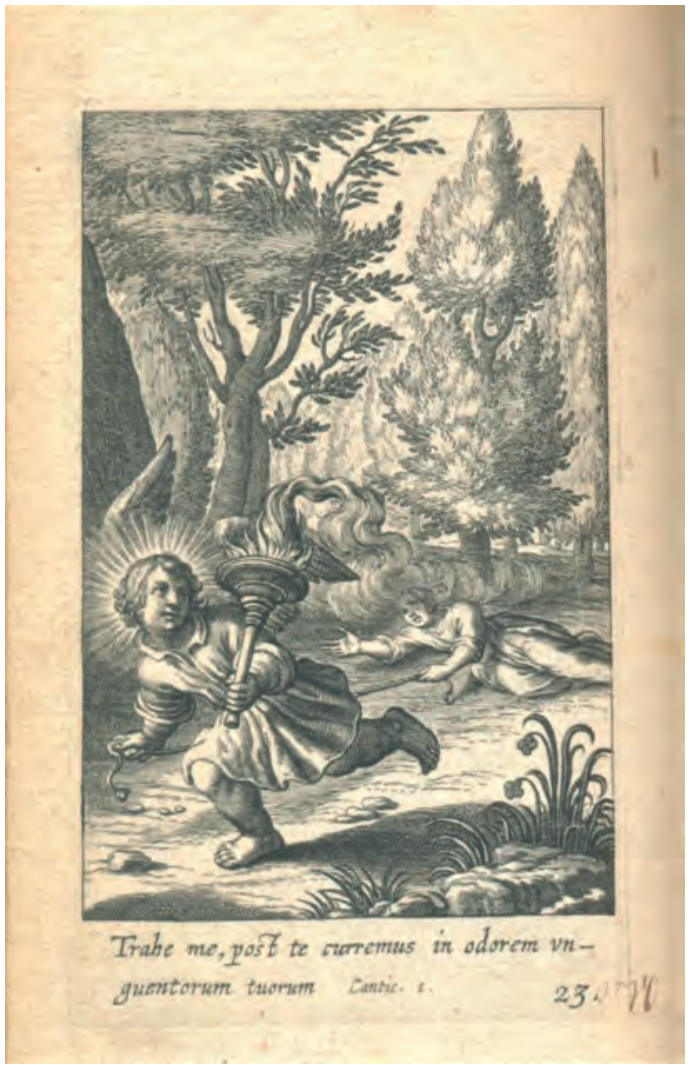

- Fig. 12. Boetius à Bolswert, Trahe me post te, curremus in odorem unguentorum tuorum. $\mathrm{H}$. HUGO, Op.cit. (emblema II, 8). Propiedad del autor.

convento de Santo António de Varatojo responde a una tendencia que se generalizó en Portugal, en especial durante el segundo cuarto del siglo XVIII, consistente en recu- rrir al empleo de composiciones emblemáticas en templos y dependencias monásticas, con series muchas veces fundamentadas en libros de emblemas, como punto de partida visual para estimular la devoción o la meditación. Si bien en algún caso tales programas son desplegados en la nave de los templos -así en la iglesia del antiguo convento de religiosas benedictinas de Nossa Senhora do Terço, en Barcelos, o en el santuario de Nossa Senhora dos Remédios, en Peniche ${ }^{58}$-, su ubicación responde por regla general a estancias auxiliares, solo accesibles, por tanto, a las comunidades monacales o cofradías -sacristías, como en este caso, salas capitulares o casas de hermandad-, lo que podría estar poniendo de manifiesto, como ya se ha señala$\mathrm{do}^{59}$, que se trate de medios de vehicular un mensaje destinado en exclusiva a un público ya iniciado. En todos los casos aparecen dispuestos para ser perfectamente visibles sin dificultad, a un nivel medio-alto de las superficies murales disponibles. Prácticamente con la excepción de Varatojo, parece resultar predominante la presencia de estos ciclos alegóricos en cenobios femeninos.

También en estas composiciones se observa una cierta inclinación a distanciarse de la apariencia marcadamente infantil de los protagonistas de los grabados de las ediciones librescas, adquiriendo sus personajes una caracterización bastante más estilizada y "juvenil", o ya decididamente adulta. Tal rasgo, en el caso de Varatojo, se manifiesta especialmente en las escenas procedentes de la Schola cordis (compárense las figuras 4 y 5), pero no así en aquellas inspiradas en los Pia desideria, mucho más fieles estas a los originales grabados (véanse figuras 11 y 12). Tal vez se entienda que la función ejemplarizante de las alegorizaciones místicas resulte

58 También encontramos composiciones dependientes de los Pia desideria revistiendo algunos pilares de la única nave de la catedral de Beja, si bien se trata de paneles reutilizados procedentes probablemente del desaparecido convento das Mónicas de Lisboa. Vid. F. BAIÔA MONTEIRO, Arte Azulejar de Beja-séculos XV a XX, Beja, 2015, p. 119.

${ }^{59}$ J. P. MONTEIRO, Op. cit., p. 67. 
más efectiva si existe una afinidad entre la apariencia de sus personificaciones y la edad de los jóvenes novicios.

Uno de los problemas más interesantes que nos plantea este programa es el de la traducción castellana de las redondillas que figuran al pie de los paneles, inspiradas en las inscriptiones latinas de Van Haeften. No ha podido localizarse hasta la fecha testimonio documental que pudiera justificar la versión española de estas estrofas en unos azulejos que, como dijimos, fueron muy probablemente realizados en un taller lisboeta. Por otra parte, resulta sorprendente el hecho de que tales composiciones sean, en principio, absolutamente originales. Hemos comentado más arriba que existe una primera edición de la Escuela del corazón publicada en Madrid en $1720^{60}$; sin embargo, un rápido cotejo entre los epigramas de esta traducción de Mecolaeta y los versos de los paneles de Varatojo permite comprobar que se trata de textos completamente diferentes, siendo una propuesta más libre, menos ajustada literalmente al original latino, la de estos últimos. No nos resulta posible ofrecer por el momento alguna hipótesis razonable sobre la autoría, o sobre las razones de la elección de nuestro idioma para las traducciones de aquellos textos emblemáticos del convento portugués.

Ya se señaló en su momento que la marcada orientación religiosa de la literatura emblemática portuguesa consolidó el empleo de las alegorizaciones pías en las prácticas de devoción, transmitiendo modelos de vida virtuosa que creaban empatía con el público ${ }^{61}$. Este tipo de libros constituye en tierras lusas una suerte de catecismos ilustrados, donde se aúnan en perfecta sintonía la finalidad evangelizadora post-tridentina, que aprovecha las ventajas de la asociación entre doctrina y plasticidad, y la fascinación

${ }^{60}$ Escuela del corazón: instrucción para que el corazón averso se convierta a Dios que escribió en latín el $P$. D. Benito Haesteno, Madrid, Imprenta Real por Joseph Rodríguez de Escobar, 1720.

${ }^{61}$ F. MEDEIROS ARAÚJO, Op. cit., p. 522. barroca por el carácter entre hermético y enigmático de la literatura de emblemas. Sin embargo, también es cierto que estas obras "disuelven" esa vertiente más erudita e intelectualizada de los emblemas al transformarse en manuales de devoción u oración de orientación marcadamente moralizante, accesibles sin dificultad a sus potenciales lectores en su lengua vernácula. Se trata de un proceso de simplificación y vulgarización del método jesuítico de meditación, apoyado en unas imágenes alegóricas reconocibles, con una dimensión cristológica manifiestamente intensificada, y en unas citas bíblicas especialmente familiares y amables -procedentes, ya dijimos, de los Salmos o del Cantar de los cantares-, que podían ajustarse con suma facilidad a una función "docente" acorde con la sensibilidad conventual.

Es esta intención la que parece trasladarse al programa de azulejos que aquí nos ocupa, a la vista, no solo de la traducción castellana -en otros casos portuguesa- de las estrofas aclaratorias, sino de una aparente tendencia a la selección de aquellos emblemas que, desde su dimensión visual, posibiliten una más rápida y sencilla comprensión y asimilación del concepto. Entre los tópicos a los que se alude en el presente programa se incluyen la necesidad de depurar las pasiones y afectos de nuestro corazón, que debe ablandarse ante la clemencia y el amor divinos y abrirse a los más benéficos y piadosos influjos; el rechazo de los deseos y tentaciones materiales y la necesidad de activar la vía contemplativa; la importancia de la práctica de virtudes como la humildad y la mansedumbre del corazón; o, en fin, la adopción del camino del sacrificio y el sufrimiento como medio más rápido y eficaz de alcanzar la gracia salvadora y la unión mística con Dios. De este modo, aquellas imágenes seguirían desempeñando la función edificante y ejemplarizante de sus equivalentes librescos, posiblemente de manera más directa y efectiva, desde los muros de los espacios vinculados a las vivencias y experiencias confesionales colectivas de sus usuarios. No parece improbable que la pre- 
sencia de este erudito programa de jeroglíficos sagrados de la sacristía del convento de Varatojo guarde estrecha relación con la función del santuario como Seminario de estudios desde finales del siglo XVII, y, como se ha dicho, con la actividad docente y literaria que frei António das Chagas desempeñó en el lugar durante los últimos años de su vida, testimonio de una cierta familiaridad con la cultura emblemática del momento.

\section{BIBLIOGRAFÍA}

AZANZA LÓPEZ, J. J. y ZAFRA MOLINA, R., Deleitando enseña: una lección de emblemática. Libros de emblemas en la Universidad de Navarra, Pamplona, 2009.

BAIÔA MONTEIRO, F., Arte Azulejar de Beja - séculos XV a XX, Beja, 2015.

BARROS VELOSO, A. J. de y AMASQUÉ, I., História e azulejos dos hospitais civis de Lisboa, Lisboa, 2016.

BELCHIOR PONTES, M. de L., Frei António das Chagas. Um Homem e um Estilo do Séc. XVII, Lisboa, 1953.

CAMPA, P. F., "The Spanish and Portuguese Adaptations of Herman Hugo's Pia Desideria", en P. M. DALY y D. S. RUSSELL (eds.), Emblematic Perceptions: Essays in Honour of William S. Heckscher on the Occasion of his Ninetieth Birthday, BadenBaden, 1997, pp. 43-60.

CARVALHO, M. do R. S. de, "A pintura do azulejo em Portugal [1675-1725]. Autorias e biografías - um novo paradigma", Tesis doctoral defendida en la Universidade de Lisboa, 2012.

DIMLER, G. R., “Herman Hugo's Pia Desideria”, en K. A. E. ENENKEL y A. S. Q. VISSER (eds.), Mundus Emblematicus. Studies in Neo-Latin Emblem Books, Turnhout, 2003, pp. 351-379.

FREITAS CARVALHO, J. A. de, “As lágrimas e as setas. Os Pia Desideria de Herman Hugo, S. J. em Portugal", Via spiritus, 2, 1995, pp. 169-201.
GARCÍA ARRANZ, J. J., “Emblemática inmaculista en la azulejería barroca portuguesa: el programa de la iglesia parroquial das Mercês de Lisboa", en I. ARRELLANO y A. MARTÍNEZ PEREIRA (eds.), Emblemática y religión en la Península Ibérica (Siglo de Oro), Bilbao, 2010, pp. 147-172.

GARCÍA ARRANZ, J. J., "Jeroglíficos en la azulejería barroca portuguesa del siglo XVIII al servicio de la retórica eclesiástica: los programas de António y Policarpo de Oliveira Bernardes", en I. RODRÍGUEZ MOYA, M. Á. FERNÁNDEZ VALLE y C. LÓPEZ CALDERÓN (eds.), Arte y patrimonio en Iberoamérica. Tráficos transoceánicos, Castelló de la Plana, 2016.

GARCÍA MAHÍQUES, R., Flora emblemática. Aproximación descriptiva del código icónico, Valencia, 1991 (2 vols., ed. en microfichas).

HAEFTEN, B. van, Schola cordis sive aversi à Deo Cordis ad eumdem reductio, et instructio, Amberes, 1629.

HUGO, H., Pia Desideria Emblematis Elegiis $\mathcal{E}$ affectibus SS. Patrum illustrata, Amberes, 1624.

ISIDORO DE SEVILLA, Etimologías, texto latino, versión española y notas de J. OROZ RETA y M. Á. MARCOS CASQUERO, Madrid, 2004 (2 vols.).

LAPIDE, C. a, Commentarii in ecclesiasten, París, 1878, IX.

LOPES, F., "Últimos días do Seminario Apostólico de Varatojo", Itinerarium, $\mathrm{n}^{\underline{0}}$ 93-94, 1976, pp. 324-338.

MARIA SANTISSIMA, M. de, Historia da Fundação do Real Convento e Seminario de Varatojo, Porto, 1799 (2 vols.).

MECO, J., Azulejaria portuguesa, Lisboa, 1985.

MECO, J., “Le `cycle des maîtres' baroques”, en R. DE SMET (ed.), Azulejos, Bruselas, 1991, pp. 41-48.

MECOLAETA, D. (trad.), Escuela del corazón: instrucción para que el corazón averso se con- 
vierta a Dios que escribió en latín el P. D. Benito Haesteno, Madrid, 1720 (2 vols.).

MEDEIROS ARAÚJO, F., Verba significant, res significantur: a receção dos Emblemata de Alciato na produção literaria do Barroco em Portugal, Tesis doctoral defendida en la Universidad de Coimbra, 2014.

MOITA, T., “Os Azulejos do Mestre P. M. P. da sacristia da igreja de Santa Cruz da Ribeira de Santarém: um itinerário místico e eucarístico", en A. GAGO da CÂMARA y S. COSTA SALDANHA (coords.), Ciclos de Iconografia Cristã na Azulejaria. Actas do I Colóquio Sacrae Imagines, Lisboa, 2013, pp. 179-188.

MONTEIRO, J. P., “Os 'Pia desideria', uma fonte iconográfica da azulejaria portuguesa do século XVIII", Azulejo, no 3/7, 1995-1999, pp. 61-70.

"MOSTEIRO de Varatojo", en Património Cultural, página web de la Direção-Geral do Património Cultural, consultada el 18 de julio de 2017. URL: http://www.patrimoniocultural.gov.pt/pt/patrimonio/ patrimonio-imovel/pesquisa-do-patrimonio/classificado-ou-em-vias-de-classificacao/geral/view/70223/.

MOURA SOBRAL, L. de, "A sacristia como pinacoteca da época barroca: o ciclo pictural de Bento Coelho no convento de S. Pedro de Alcântara, Lisboa", en Do sentido das imagens. Ensaios sobre pintura barroca portuguesa e outros temas ibéricos, Lisboa, 1996, pp. 81-96.

MOURA SOBRAL, L. de, "Tota pulchra est amica mea. Simbolismo e narração num programa imaculista de António de Oliveira Bernardes", Azulejo, nº 3/7, 19951999, pp. 71-90.

PEREIRA VELOSO, J., Desejos piedosos de huma alma saudosa do seu divino Esposo Jesu Christo, Lisboa, 1687.

PICINELLI, F., Mondo simbolico, Milán, 1680.

PLINIO EL VIEJO, C., Historia natural. Libros XII-XVI, F. MANZANERO CANO, I. GARCÍA ARRIBAS, M. L. ARRIBAS HERNÁEZ, A. M. MOURE CASAS y J. L. SANCHO BERMEJO (trad. y notas), Madrid, 2010.

PRAZ, M., Imágenes del Barroco. Estudios de Emblemática, Madrid, 1989.

RIBEIRO, B., Convento de Santo António de Varatojo, Torres Vedras, 2005.

SALAS, P. de, Affectos divinos con emblemas sagradas, Valladolid, 1658.

SANTOS SIMÕES, J. M. dos, Azulejaria em Portugal no século XVIII, Lisboa, 1979.

SEBASTIÁN LÓPEZ, S., "Los emblemas del Camino real de la Cruz de Van Haeften", Boletín del Museo e Instituto "Camón Aznar», vol. XLIV, 1991, pp. 5-64,

SPICA, A. E., Symbolique humaniste et emblematique: L'evolution et les genres (15801700), Paris, 1996.

SUETONIO TRANQUILO, C. Vidas de los Césares, V. PICÓN (ed.), Madrid, 2008.

VALERIANO, G. P., Hieroglyphica sive de sacris aegyptiorum, aliarumque gentium literis commentarii, Basilea, Thomam Guarinum, 1567. 